\title{
Catalytic Chemical Vapor Deposition of Single-Wall Carbon Nanotubes at Low Temperatures
}

2006

Vol. 6, No. 6

$1107-1112$

\author{
Mirco Cantoro, ${ }^{\dagger}$ Stephan Hofmann, ${ }^{*, \dagger}$ Simone Pisana, ${ }^{\dagger}$ Vittorio Scardaci, ${ }^{\dagger}$ \\ Atlus Parvez, ${ }^{\dagger}$ Caterina Ducati, ${ }^{\ddagger}$ Andrea C. Ferrari, ${ }^{\dagger}$ Arthur M. Blackburn, $\$$ \\ Kai-You Wang, ${ }^{\S}$ and John Robertson ${ }^{\dagger}$
}

Electrical Engineering Division, University of Cambridge, Cambridge CB3 OFA, U.K.,

Department of Materials Science and Metallurgy, University of Cambridge,

Cambridge CB2 3QZ, U.K., and Hitachi Cambridge Laboratory,

Cambridge CB3 OHE, U.K.

Received January 11, 2006; Revised Manuscript Received March 24, 2006

\begin{abstract}
We report surface-bound growth of single-wall carbon nanotubes (SWNTs) at temperatures as low as $350{ }^{\circ} \mathrm{C}$ by catalytic chemical vapor deposition from undiluted $\mathrm{C}_{2} \mathrm{H}_{2} . \mathrm{NH}_{3}$ or $\mathrm{H}_{2}$ exposure critically facilitates the nanostructuring and activation of sub-nanometer $\mathrm{Fe}$ and $\mathrm{Al} / \mathrm{Fe} / \mathrm{Al}$ multilayer catalyst films prior to growth, enabling the SWNT nucleation at lower temperatures. We suggest that carbon nanotube growth is governed by the catalyst surface without the necessity of catalyst liquefaction.
\end{abstract}

Carbon nanotubes (CNTs) have been a driving force for current advances in nanotechnology, both on an applied and on a fundamental level. Single-wall carbon nanotubes have shown the highest Young's modulus and highest axial thermal conductivity of any solid. Moreover, SWNTs have the highest current carrying capacity of any conductor, which makes them an attractive electronic, sensing, or heat sinking material for nano-electromechanical systems (NEMS) and future (hybrid) integrated circuitry. ${ }^{1,2}$

Defect-free SWNT synthesis is generally thought to require high temperatures (T). ${ }^{3}$ This belief arises from the success of high-T deposition processes. Arc-discharge, laser ablation, and high-pressure $\mathrm{CO}$ conversion with inherent (local) temperatures in the order of $1000-4000{ }^{\circ} \mathrm{C}$ have been optimized mainly for bulk CNT production. ${ }^{3}$ For device fabrication, these techniques heavily rely on purification from other carbon allotropes and an indirect postgrowth assembly via stable suspensions. In comparison, catalytic chemical vapor deposition (CVD) allows selective, aligned CNT growth directly onto a substrate and thus presently is the only economically viable process for integrating CNTs into a device. ${ }^{1,4-6}$ This approach, however, exposes the substrate to the CNT growth temperature and atmosphere, which

* To whom correspondence may be addressed. E-mail: sh315@ cam.ac.uk.

Electrical Engineering Division, University of Cambridge.

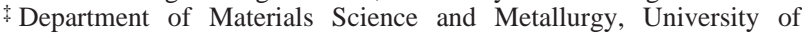
Cambridge.

$\S$ Hitachi Cambridge Laboratory. creates a need for less aggressive, low $\mathrm{T}$ processing conditions. Present back-end CMOS technology allows a maximum temperature of $400-450^{\circ} \mathrm{C}$, the limit being set by the mechanical integrity of low dielectric constant intermetal dielectrics. $^{7}$

Thermal CVD of SWNTs has been reported at $550{ }^{\circ} \mathrm{C}$ in furnace $^{8}$ and cold wall systems. ${ }^{9}$ In situ environmental transmission electron microscopy (TEM) experiments show SWNT nucleation at $480{ }^{\circ} \mathrm{C} .{ }^{10}$ Random-network FETs have been fabricated with SWNTs grown at $450{ }^{\circ} \mathrm{C}$ by remote plasma-enhanced (PE) CVD. ${ }^{11}$ However, the high temperatures of bulk production techniques still dominate growth model considerations with the assumption that the catalyst cluster has to be liquefied and that the catalyst bulk is ratecontrolling. ${ }^{12,13}$ These considerations are also transferred to surface-bound CVD. ${ }^{14} \mathrm{CNT}$ growth below $500{ }^{\circ} \mathrm{C}$ is not thought to be possible based on calculations of size-corrected melting points ${ }^{14}$ and carbon saturation. ${ }^{15}$

In this Letter, we report SWNT growth at temperatures below $450{ }^{\circ} \mathrm{C}$ by thermal CVD at cold wall conditions and demonstrate field effects in as-integrated SWNT FETs. We use evaporated thin catalyst films, which allow accurate patterning by standard lithography techniques and thus compatibility with integrated circuit design. The restructuring of a solid thin film into catalytically active islands requires mobility and thus thermal activation, which should be distinguished from the low-temperature limit of the actual SWNT nucleation. We show that $\mathrm{NH}_{3}$ or $\mathrm{H}_{2}$ exposure 

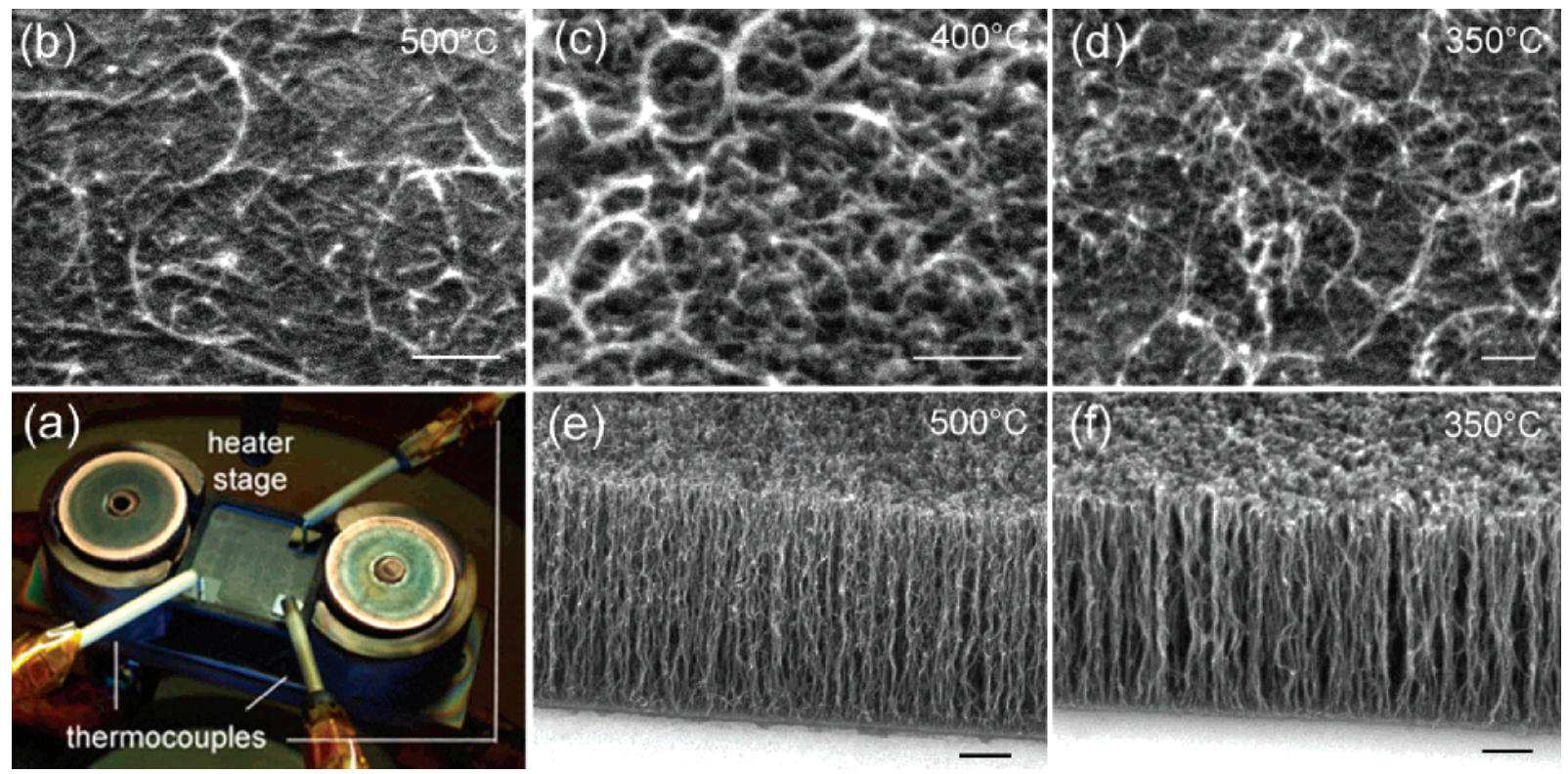

Figure 1. (a) Graphite heater stage with shielded thermocouples. (b-f) SEM images of SWNTs thermally grown in undiluted $\mathrm{C}_{2} \mathrm{H}_{2}$ for 5 min from (b-d) $0.3 \mathrm{~nm} \mathrm{Fe}$, (e) Al/Fe $(0.5 \mathrm{~nm}) / \mathrm{Al}$ (top, $0.2 \mathrm{~nm}$ ), and (f) $\mathrm{Al} / \mathrm{Fe}(0.3 \mathrm{~nm}$ )/Al (top, $0.2 \mathrm{~nm})$ multilayers on $\mathrm{Si} / \mathrm{SiO}{ }_{2}$ substrates. The catalyst films are annealed in $\mathrm{NH}_{3}$ at $(\mathrm{b}-\mathrm{d}, \mathrm{f}) 0.6 \mathrm{mbar}$ and (e) 20 mbar, prior to SWNT growth. The process temperature is indicated for each sample. Scale bars: $100(b-d), 500(e)$, and $200 \mathrm{~nm}(\mathrm{f})$.

critically affects the dewetting and activation of subnanometer $\mathrm{Fe}$ and $\mathrm{Al} / \mathrm{Fe} / \mathrm{Al}^{16}$ multilayers on $\mathrm{Si} / \mathrm{SiO}_{2}$ substrates upon temperature elevation, enabling an appropriate catalyst nanostructuring at low temperatures. SWNT growth is observed at temperatures as low as $350{ }^{\circ} \mathrm{C}$ upon subsequent exposure to pure $\mathrm{C}_{2} \mathrm{H}_{2}$ at low pressures $\left(<10^{-2}\right.$ mbar). Raman analysis shows that such low temperature growth leads to a narrower SWNT diameter and possibly SWNT chirality distribution, confirming trends observed by other groups. ${ }^{8,17,18}$ Combined with previous ab initio calculations, ${ }^{19}$ we suggest that surface, rather than bulk catalyst effects, dominate SWNT growth kinetics in surface-bound CVD.

We use polished, 0.01-0.02 $\Omega \mathrm{cm}$ boron-doped $\mathrm{Si}(100)$ wafers as substrates, covered with thermally grown $\mathrm{SiO}_{2}$ $(\sim 50-200 \mathrm{~nm})$. The $\mathrm{SiO}_{2}$ layer can prevent uncontrolled silicide formation ${ }^{20}$ and serves as gate dielectric for FET fabrication. High-purity $\mathrm{Fe}, \mathrm{Co}$, and $\mathrm{Ni}$ catalyst films and $\mathrm{Al}$ layers are deposited by thermal evaporation. The evaporation rate is $<1 \AA / \mathrm{s}$ at $<10^{-6} \mathrm{mbar}$ base pressure. No substrate heating is used during evaporation. The film thickness is monitored in situ by a quartz crystal microbalance and calibrated ex situ by atomic force microscopy (AFM, Digital Instruments Nanoscope III and Veeco Explorer) and spectroscopic ellipsometry (J. A. Woollam Co., M-2000 V). The catalyst films are patterned by optical or e-beam lithography using S1813 or PMMA as resist. The substrates are transferred in air and loaded onto a resistively heated graphite stage (Figure 1a). The stainless steel CVD chamber is diffusion pumped (base pressure $<10^{-6} \mathrm{mbar}$ ) with massflow-controlled gas feeds.

The temperature is continuously monitored by three shielded thermocouples distributed across reference $\mathrm{Si}$ substrates (500 $\mu \mathrm{m}$ in thickness, equivalent to samples) and the graphite heater, Figure 1a. All temperatures indicated refer to the substrate surface temperature measured on top of the $\mathrm{Si}$ and not to the heater block (which has higher $\mathrm{T}$ for a typical poor thermal contact) and thus truly represent the catalyst temperature. It is known from general heterogeneous catalysis that significant temperature differences between an individual catalyst particle and its support will not exist under realistic conditions of rate and size. ${ }^{21}$ This holds for exothermic feed-gas dissociation as well as plasma heating.

The catalyst film is heated in $\mathrm{NH}_{3}$ (grade 5, 0.6-20 mbar) or $\mathrm{H}_{2}$ (VLSI grade, $0.6-100 \mathrm{mbar}$ ) for typically $15 \mathrm{~min}$ to equilibrate the desired growth temperature. For some samples, catalyst reconstruction is aided by a dc plasma excitation for $\sim 30 \mathrm{~s}(<15 \mathrm{~W}$ power). The chamber is then evacuated and undiluted $\mathrm{C}_{2} \mathrm{H}_{2}$ (AA grade, $99.6 \%$ purity) is allowed to flow from a side gas inlet at $10^{-3}-10^{-2}$ mbar. After a growth period of $5 \mathrm{~min}$, the samples are cooled in vacuum.

The samples are characterized by scanning electron microscopy (SEM, LEO 1530VP FEGSEM), high-resolution (HR) TEM (JEOL JEM 4000EX, $400 \mathrm{kV}$; FEI Tecnai F20, $200 \mathrm{kV}$ ), and Raman spectroscopy (Renishaw 1000 Raman spectrometer, 514.5, 633, and $785 \mathrm{~nm}$ excitation). For HRTEM analysis, SWNTs are either removed from the substrates and dispersed onto lacey carbon TEM grids or grown directly onto e-beam transparent, $50 \mathrm{~nm}$ thick silicon nitride membranes (Agar Scientific).

$\mathrm{Ti}$ and Pd source and drain contacts for FET devices are sputter-deposited or evaporated through a PMMA lift-off mask, to create contact separations in the range of 300-800 $\mathrm{nm}$. Electrical characteristics are collected at ambient conditions.

SWNT nucleation requires nanometer-sized catalyst island dimensions ${ }^{22-24}$ and thus a very thin initial catalyst film..$^{25}$ 

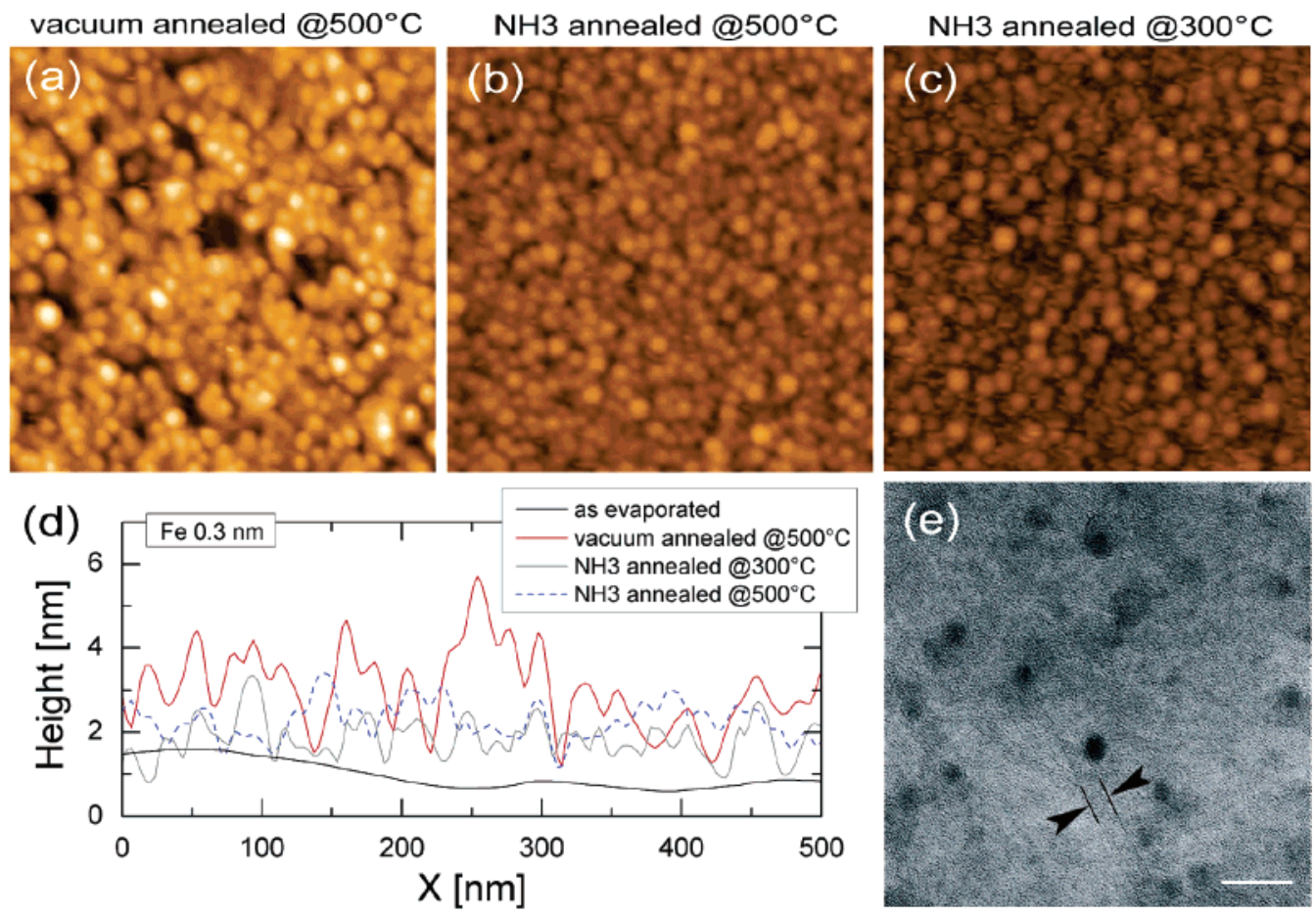

Figure 2. AFM topography images of (a) $500{ }^{\circ} \mathrm{C}$ vacuum $\left(<10^{-5}\right.$ mbar) annealed, (b) $500{ }^{\circ} \mathrm{C} \mathrm{NH}_{3}\left(0.6\right.$ mbar) annealed, and (c) $300{ }^{\circ} \mathrm{C}$ $\mathrm{NH}_{3}(0.6 \mathrm{mbar})$ annealed $0.3 \mathrm{~nm} \mathrm{Fe}$ on $\mathrm{Si} / \mathrm{SiO}_{2}$. (d) AFM line sections of as-evaporated $0.3 \mathrm{~nm}$ Fe and samples shown in (a-c). All AFM image dimensions are $500 \times 500 \mathrm{~nm}^{2}$ with identical $z$ scale. (e) HRTEM image of $0.1 \mathrm{~nm}$ Fe on $50 \mathrm{~nm}$ thick silicon nitride membrane after annealing in $\mathrm{NH}_{3}(0.6 \mathrm{mbar})$ and exposure to undiluted $\mathrm{C}_{2} \mathrm{H}_{2}$ for 5 min at $500{ }^{\circ} \mathrm{C}$. The arrows mark a SWNT (scale bar: $10 \mathrm{~nm}$ ).

Larger metal clusters can catalyze MWNTs and CNFs. ${ }^{25}$ Parts $b-d$ of Figure 1 show SEM images of SWNTs nucleated from a $0.3 \mathrm{~nm}$ Fe film on $\mathrm{Si} / \mathrm{SiO}_{2}$ substrates. A transition from long, bundled SWNTs distributed mainly laterally on the substrate (Figure $1 \mathrm{~b}, \mathrm{c}$ ) to a mixture of SWNTs and more vertically extended, thicker MWNTs/ CNFs (Figure 1d) is observed with decreasing growth temperature. The lowest temperature at which we could detect SWNTs by HRTEM and Raman spectroscopy is 350 ${ }^{\circ} \mathrm{C}$ (Figure 3). Parts e and $\mathrm{f}$ of Figure 1 show evaporated $\mathrm{Al} / \mathrm{Fe} / \mathrm{Al}$ multilayers after processing in similar growth conditions to the pure Fe films (Figure $1 \mathrm{~b}, \mathrm{~d}$ ). The CNT yield is much higher, resulting in vertical alignment due to van der Waals interactions of neighboring nanotubes. At given CVD conditions, preannealing the catalyst in a vacuum $\left(<10^{-5}\right.$ mbar pressure) leads to no CNT growth.

$\mathrm{NH}_{3}$ and $\mathrm{H}_{2}$ have often been used as diluents during CNT growth, in particular for PECVD; ${ }^{26,27}$ here we focus on their role in catalyst restructuring prior to growth. Parts $a-d$ of Figure 2 show AFM topography and line sections of $0.3 \mathrm{~nm}$ thick Fe as-evaporated and after annealing in different atmospheres and temperatures. The AFM measurements are performed in tapping mode at ambient conditions and therefore include the effects of oxidation. ${ }^{28}$ At $500{ }^{\circ} \mathrm{C}$, the $\mathrm{NH}_{3}$ annealed $\mathrm{Fe}$ film (Figure $2 \mathrm{~b}$ ) shows smaller average island dimensions than for vacuum annealing (Figure 2a). Within the limits of the AFM analysis, annealing in $\mathrm{NH}_{3}$ at $300{ }^{\circ} \mathrm{C}$ results in cluster sizes (Figure 2c) similar to the distribution at $500{ }^{\circ} \mathrm{C}$ (Figure 2b). Sub-nanometer films generally nucleate in a Volmer-Weber mode on $\mathrm{SiO}_{2}$ and thus can be discontinuous as-evaporated. Thin solid films dewet driven by surface and elastic energy minimization ${ }^{29}$ the resulting islands sinter due to ripening or migration. ${ }^{30}$ These processes tend to scale with the melting temperature. As a rule of thumb, Huettig and Tamman temperatures are semiempirically defined as 0.3 and 0.5 times the melting point in $\mathrm{K}$, respectively, to indicate the temperature at which atoms become mobile at defects $\left(269{ }^{\circ} \mathrm{C}\right.$ for $\left.\mathrm{Fe}\right)$ or in the bulk $\left(631{ }^{\circ} \mathrm{C}\right.$ for $\left.\mathrm{Fe}\right){ }^{31}$ This neglects substrate interactions ${ }^{20,32}$ and the fact that for small particles mobility occurs at much lower temperatures. ${ }^{33,34} \mathrm{NH}_{3}$ or $\mathrm{H}_{2}$ exposure reduces initially oxidized $\mathrm{Fe}$ and facilitates surface mobility of metal atoms and clusters. ${ }^{35}$ Adsorbed gases in general can act as "surfactants", modifying surface energies. ${ }^{36}$ As Figure 2 shows, thin films form small catalyst islands at very low temperatures. We find $\mathrm{H}_{2}$ to require higher pressures for thermal catalyst activation, which can be compensated by a weak plasma excitation to etch and enhance catalyst reconstruction. ${ }^{25,37}$

An Al underlayer (Tamman T $194{ }^{\circ} \mathrm{C}$ ) enhances SWNT yield (Figure 1e,f) by clustering itself, thereby increasing the catalyst support surface area and decreasing the probability of catalyst sintering. ${ }^{38}$ The $\mathrm{Al}$ surface is (at least) partly oxidized during sample transfer after evaporation, forming a stable alumina-catalyst interface. An (oxidized) $\mathrm{Al}$ top layer additionally stabilizes small Fe clusters ${ }^{16}$ and thus increases SWNT yield (Figure 1e,f) compared to nonAl-topped Al/Fe bilayers (results not shown here). Preliminary results on sub-nanometer $\mathrm{Ni}$ and Co films indicate less efficient SWNT nucleation, which might be related to different catalyst-substrate interactions for the used growth conditions. 

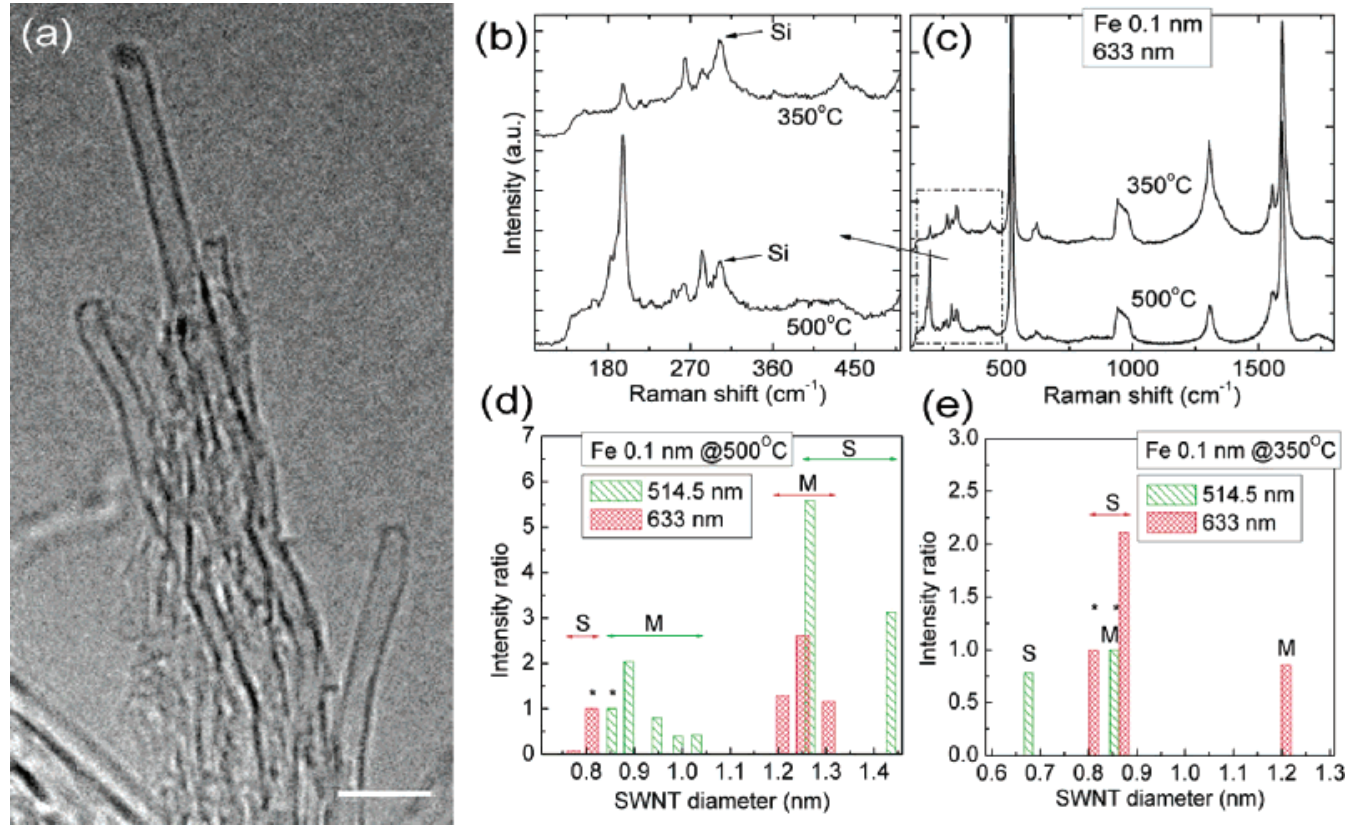

Figure 3. (a) HRTEM image of SWNTs thermally grown at $350{ }^{\circ} \mathrm{C}$ for 5 min in undiluted $\mathrm{C}_{2} \mathrm{H}_{2}$ from a $\mathrm{NH}_{3}(0.6$ mbar pressure) annealed $\mathrm{Al} / \mathrm{Fe}(0.3 \mathrm{~nm}) / \mathrm{Al}$ (top, $0.2 \mathrm{~nm}$ ) multilayer on $\mathrm{Si} / \mathrm{SiO}_{2}$ (scalebar: $10 \mathrm{~nm}$ ). A SEM image of the sample has been shown in Figure 1f. (b, c) Raman spectra $\left(633 \mathrm{~nm}\right.$ excitation) of SWNTs grown at 500 and $350{ }^{\circ} \mathrm{C}$ from $0.1 \mathrm{~nm} \mathrm{Fe}$ on $\mathrm{Si} / \mathrm{SiO}_{2}$ (the peaks assigned to the $\mathrm{Si}$ substrate are indicated). (d, e) Relative abundances of different SWNT diameters at 500 and $350{ }^{\circ} \mathrm{C}$, respectively (514.5 and $633 \mathrm{~nm}$ excitation). The assignment of semiconducting (S) and metallic (M) SWNTs and reference intensities $(*)$ are indicated.

Catalyst reduction can also occur due to hydrogen liberated from the catalytic decomposition of $\mathrm{C}_{2} \mathrm{H}_{2} \cdot{ }^{32}$ For high SWNT CVD temperatures, metal clusters are often deliberately kept oxidized prior to growth to stabilize them against excessive sintering. Metal oxides show a stronger interaction with oxidized substrates and therefore lower mobility. ${ }^{35}$ For our conditions, however, the vacuum-annealed samples show larger catalyst clusters (Figure 2) and no SWNT nucleation at low temperatures. A careful monitoring of the catalyst activation is thus essential when comparing different CVD conditions.

Chemisorbed $\mathrm{H}$ can additionally lead to temperature- and pressure-dependent catalyst surface reconstruction, thus altering its interaction with $\mathrm{C}_{2} \mathrm{H}_{2} \cdot{ }^{39}$ Hydrogen penetration into subsurface layers can loosen the catalyst surface ${ }^{39}$ and may give higher carbon diffusivities for low-temperature SWNT nucleation. ${ }^{19}$

Figure 2e shows a HRTEM image of a $0.1 \mathrm{~nm}$ Fe film on an e-beam transparent silicon nitride membrane after SWNT $\mathrm{CVD}$ at $500{ }^{\circ} \mathrm{C}$. A low-density distribution of sub-3-nm Fe particles is formed. As-nucleated SWNTs have diameters ranging from 1.2 to $2.3 \mathrm{~nm}$. It has to be emphasized that depending on the wetting behavior the catalyst island shape can be highly anisotropic and that the high metal mobility leads to catalyst reshaping upon graphene formation during CVD. ${ }^{23,40}$ Thus the postgrowth catalyst structure indicates SWNT nucleation $\operatorname{sites}^{23}$ but is not representative of the initial catalyst morphology. Within the limited number of processed silicon nitride substrates, we observe a SWNT yield similar to silicon oxide supports.

Figure 3a shows a HRTEM image of SWNTs nucleated at $350^{\circ} \mathrm{C}$. We find closed SWNT tips, some of which present a spherical catalyst particle, suggesting a tip growth model. Even though there is a large variation in their morphology, some SWNTs show a remarkable crystallinity, with clean parallel walls. Parts b and c of Figure 3 compare the Raman spectra (633 nm excitation) of samples grown at 350 and $500{ }^{\circ} \mathrm{C}$ from $0.1 \mathrm{~nm} \mathrm{Fe}$. Both spectra show radial breathing modes (RBMs) (Figure 3b) and a structured G peak (Figure 3c). ${ }^{41,42}$ More defects and disordered graphitic material are present for the lowest growth temperature, as indicated by the larger, more structured D peak, consistent with Figure 1d. Parts $d$ and e of Figure 3 compare the relative ${ }^{43}$ abundance of metallic and semiconducting SWNTs seen by Raman spectroscopy as a function of deposition temperature. We derive the SWNT diameter by $d=C_{1} /\left(\omega_{\mathrm{RBM}}-C_{2}\right)$, with $C_{1}=214.4 \mathrm{~nm} \mathrm{~cm}^{-1}$ and $C_{2}=18.7 \mathrm{~cm}^{-1} 42$ and assign based on the Kataura plot ${ }^{44}$ and the known excitation energy. ${ }^{45}$ A RBM analysis of a large range of different catalyst film thicknesses and CVD temperatures shows that by lowering $\mathrm{T}$ and the amount of evaporated $\mathrm{Fe}$ we get smaller average SWNT diameters with a narrower distribution. This is consistent with the catalyst coarsening behavior (Figure 2) and the HRTEM analysis (Figures 2e and 3a) and confirms trends reported for pulsed laser deposition at much higher temperatures ${ }^{46}$ and by CVD at $550-850{ }^{\circ} \mathrm{C} .{ }^{8,17,18} \mathrm{We}$ stress that due to the cutoff of our notch filter, we cannot detect SWNT diameters $>2 \mathrm{~nm}$.

Figure 4 shows back-gated FET devices and typical $I_{\mathrm{ds}}-$ $V_{\mathrm{gs}}$ characteristics from $\sim 5 \mu \mathrm{m}$ wide strips of randomnetwork SWNT carpets nucleated from $0.1 \mathrm{~nm}$ thick Fe at different temperatures. To selectively burn metallic CNTs and thus increase the $I_{\mathrm{ds}(\text { on })} / I_{\mathrm{ds}(\text { off })}$ ratio, ${ }^{47}$ we apply a positive $V_{\mathrm{gs}}$ which turns off the semiconducting SWNTs (these show 

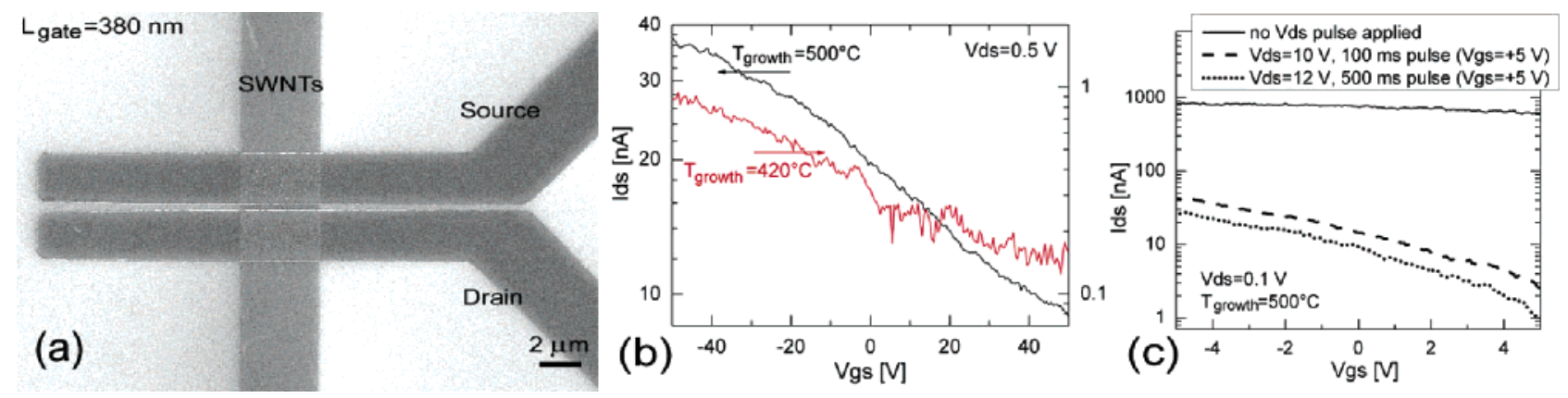

Figure 4. Back-gated FETs and their $I_{\mathrm{ds}}-V_{\mathrm{gs}}$ characteristics based on random-network SWNT carpets nucleated from $\mathrm{H}_{2}$ plasma pretreated (a, b) and $\mathrm{NH}_{3}$-annealed (c) $0.1 \mathrm{~nm}$ thick Fe films, exposed to $5 \mathrm{sccm}$ of $\mathrm{C}_{2} \mathrm{H}_{2}$ for $5 \mathrm{~min}$ at $500{ }^{\circ} \mathrm{C}$ and $420{ }^{\circ} \mathrm{C}$. Sputtered Ti source/drain contacts are $30 \mathrm{~nm}$ thick with a separation of $\sim 400 \mathrm{~nm}$ on a $200 \mathrm{~nm}$ thick $\mathrm{SiO}_{2}$ gate, and the respective devices are measured after a $V_{\mathrm{ds}}$ $=0-10 \mathrm{~V}$ burning sweep $\left(V_{\mathrm{gs}}=+50 \mathrm{~V}\right)(\mathrm{a}, \mathrm{b})$. Evaporated Pd source/drain contacts are $30 \mathrm{~nm}$ thick with a separation of $\sim 640 \mathrm{~nm}$ on a $50 \mathrm{~nm}$ thick $\mathrm{SiO}_{2}$ gate (c). The gate-leakage current is $<10 \mathrm{pA}$.

p-type characteristics in air) and then apply a large $V_{\mathrm{ds}}$. The as-conditioned devices show a very consistent p-type gating behavior, although the $I_{\mathrm{ds}(\mathrm{on})} / I_{\mathrm{ds}(\text { off })}$ ratio is not yet much beyond 20 . We are currently optimizing contact formation ${ }^{48}$ and SWNT network density. Also a shorter gate length is desirable to achieve high conductance through directly bridging SWNTs ${ }^{49}$ rather than allowing percolation conduction to define device operation. ${ }^{50}$ An optimized (pregrowth) catalyst nanostructuring, a lower $\mathrm{C}_{2} \mathrm{H}_{2}$ partial pressure, ${ }^{10,24}$ and additional diluent ${ }^{11}$ can lower the SWNT defect density and minimize deleterious MWNTs/CNFs contributions.

The commonly accepted CNT growth model constitutes a rare example of a catalytic reaction in which the rate is believed to be controlled by diffusion through the catalyst bulk. ${ }^{12-15,51}$ The idea of catalyst liquefaction ${ }^{14}$ originates from the vapor liquid solid (VLS) model originally proposed for the growth of semiconductor whiskers. ${ }^{52}$ A liquid catalyst seed thereby acts as preferential adsorption site of gaseous precursors, and the growth of a solid nanostructure is thought to occur through precipitation at the liquid-solid interface. We previously showed that CNF CVD is possible well below the size-corrected melting points of mesoscale $\mathrm{Ni}, \mathrm{Co}$, and $\mathrm{Fe}$ catalysts clusters, ${ }^{19,53,54}$ even if saturated with carbon, ${ }^{55}$ and suggested that CNF nucleation, like most processes in heterogeneous catalysis, is dominated by the catalyst surface ${ }^{19}$ Here we suggest that SWNT growth is mediated by similar surface processes.

As discussed for thin film dewetting (Figure 2), small catalyst particles can continuously change shape and surface in a "fluidlike" behavior. ${ }^{33,40}$ Although highly mobile, the metal clusters are not amorphous (as one would expect for a molten phase) but crystalline, in particular for surfacebound, low-temperature CVD where catalyst-substrate and catalyst $-\mathrm{CNT}$ interactions are relevant. ${ }^{23,40}$ Without comparing the detailed sticking coefficients of the CVD gas precursors on substrate and catalyst, it can be argued that CNTs grow selectively on the catalyst as it is the only location where the barrier for thermal precursor dissociation is low enough to support a controlled carbon flux. ${ }^{19}$ The final arrangement of the carbon atoms in a rolled graphene structure is controlled by the surface of the metal particle and its shape, which in turn can change with increasing carbon coverage..$^{23,40}$ The smaller the catalyst cluster, the more dominant its surface. Independent of a definition of solid, liquid phase, or surface premelting, it can be expected that catalytic SWNT growth is governed by surface processes. Following our original argument, ${ }^{19}$ recent molecular dynamics simulations of a $1 \mathrm{~nm} F e$ nanoparticle show negligible carbon penetration into the catalyst bulk and that SWNT growth is fed by fast carbon diffusion on the catalyst surface..$^{56}$ No supersaturation-segregation process is necessary. Chemisorbed species such as $\mathrm{H}$ can significantly alter a catalyst surface $^{39}$ and thus aid diffusive transport and SWNT nucleation dependent on temperature and pressure.

To summarize, we showed the critical effects of $\mathrm{NH}_{3}$ or $\mathrm{H}_{2}$ on $\mathrm{Fe}$ thin film catalyst restructuring, enabling lowtemperature SWNT CVD and opening new possibilities for direct device integration. Conceptually, a liquid catalystcarbon eutectic is not a necessity; SWNT growth is dominated by surface processes. The findings extend to catalytic growth of anisotropic nanostructures in general. ${ }^{57}$

Acknowledgment. The work was supported by the EU project CANAPE. S.H. acknowledges funding from Peterhouse, Cambridge, V.S. from EPSRC Grant GR/S97613, and C.D. and A.C.F. from The Royal Society. C.D. thanks FEI Company, EPSRC, Isaac Newton Trust for the use of the Tecnai TEM.

\section{References}

(1) Tseng, Y. C.; Xuan, P. Q.; Javey, A.; Malloy, R.; Wang, Q.; Bokor, J.; Dai, H. J. Nano Lett. 2004, 4, 123.

(2) Sazonova, V.; Yaish, Y.; Ustunel, H.; Roundy, D.; Arias, T. A.; McEuen, P. L. Nature 2004, 431, 284.

(3) Dresselhaus, M. S.; Dresselhaus, G.; Avouris, P. Carbon Nanotubes: Synthesis, Structure, Properties and Applications; Springer: New York, 2000.

(4) Dai, H. J. Acc. Chem. Res. 2002, 35, 1035.

(5) Jung, Y. J.; Homma, Y.; Ogino, T.; Kobayashi, Y.; Takagi, D.; Wei, B. Q.; Vajtai, R.; Ajayan, P. M. J. Phys. Chem. B 2003, 107, 6859.

(6) Peng, H. B.; Ristroph, T. G.; Schurmann, G. M.; King, G. M.; Yoon, J.; Narayanamurti, V.; Golovchenko, J. A. Appl. Phys. Lett. 2003, 83,4238

(7) Morgen, M.; Ryan, E. T.; Zhao, J. H.; Hu, C.; Cho, T. H.; Ho, P. S. Annu. Rev. Mater. Sci. 2000, 30, 645.

(8) Maruyama, S.; Kojima, R.; Miyauchi, Y.; Chiashi, S.; Kohno, M. Chem. Phys. Lett. 2002, 360, 229.

(9) Liao, H. W.; Hafner, J. H. J. Phys. Chem. B 2004, 108, 6941.

(10) Sharma, R.; Rez, P.; Treacy, M. M. J.; Stuart, S. J. J. Electron Microsc. 2005, 54, 231.

(11) Min, Y.-S.; Bae, E.-J.; Oh, B. S.; Kang, D.; Park, W. J. Am. Chem. Soc. 2005, 127, 12498. 
(12) Gavillet, J.; Loiseau, A.; Journet, C.; Willaime, F.; Ducastelle, F.; Charlier, J. C. Phys. Rev. Lett. 2001, 8727, 275504

(13) Kanzow, H.; Ding, A. Phys. Rev. B 1999, 60, 11180.

(14) Harutyunyan, A. R.; Tokune, T.; Mora, E. Appl. Phys. Lett. 2005 , 87, 051919 .

(15) Klinke, C.; Bonard, J.-M.; Kern, K. Phys. Rev. B 2005, 71, 035403.

(16) Zhong, G. F.; Iwasaki, T.; Honda, K.; Furukawa, Y.; Ohdomari, I.; Kawarada, H. Jpn. J. Appl. Phys. 2005, 44, 1558.

(17) Bachilo, S. M.; Balzano, L.; Herrera, J. E.; Pompeo, F.; Resasco, D. E.; Weisman, R. B. J. Am. Chem. Soc. 2003, 125, 11186.

(18) Miyauchi, Y. H.; Chiashi, S. H.; Murakami, Y.; Hayashida, Y.; Maruyama, S. Chem. Phys. Lett. 2004, 387, 198.

(19) Hofmann, S.; Csanyi, G.; Ferrari, A. C.; Payne, M. C.; Robertson, J. Phys. Rev. Lett. 2005, 95, 036101.

(20) Liehr, M.; Lefakis, H.; Legoues, F. K.; Rubloff, G. W. Phys. Rev. B 1986, 33, 5517.

(21) Holstein, W. L.; Boudart, M. Lat. Am. J. Chem. Eng. Appl. Chem. 1983, 13, 107.

(22) Li, Y. M.; Kim, W.; Zhang, Y. G.; Rolandi, M.; Wang, D. W.; Dai, H. J. J. Phys. Chem. B 2001, 105, 11424.

(23) Zhu, H.; Suenaga, K.; Hashimoto, A.; Urita, K.; Hata, K.; Iijima, S. Small 2005, $1,1180$.

(24) Lin, M.; YingTan, J. P.; Boothroyd, C.; Loh, K. P.; Tok, E. S.; Foo, Y.-L. Nano Lett. 2006, 6, 449.

(25) Hofmann, S.; Cantoro, M.; Kleinsorge, B.; Casiraghi, C.; Parvez, A.; Robertson, J.; Ducati, C. J. Appl. Phys. 2005, 98, 034308.

(26) Wang, Y. Y.; Gupta, S.; Nemanich, R. J. Appl. Phys. Lett. 2004, 85, 2601.

(27) Zhang, G.; Mann, D.; Zhang, L.; Javey, A.; Li, Y.; Yenilmez, E.; Wang, Q.; McVittie, J. P.; Nishi, Y.; Gibbons, J.; Dai, H. Proc. Natl. Acad. Sci. U.S.A. 2005, 102, 16141.

(28) Wang, C. M.; Baer, D. R.; Thomas, L. E.; Amonette, J. E.; Antony, J.; Qiang, Y.; Duscher, G. J. Appl. Phys. 2005, 98, 094308.

(29) Jiran, E.; Thompson, C. V. J. Electron. Mater. 1990, 19, 1153.

(30) Wen, J. M.; Evans, J. W.; Bartelt, M. C.; Burnett, J. W.; Thiel, P. A. Phys. Rev. Lett. 1996, 76, 652.

(31) Moulijn, J. A.; van Diepen, A. E.; Kapteijn, F. Appl. Catal., A 2001, 212,3 .

(32) de los Arcos, T.; Garnier, M. G.; Seo, J. W.; Oelhafen, P.; Thommen, V.; Mathys, D. J. Phys. Chem. B 2004, 108, 7728.

(33) Iijima, S.; Ichihashi, T. Phys. Rev. Lett. 1986, 56, 616.

(34) Smith, D. J. J. Vac. Sci. Technol., B 1985, 3, 1563.

(35) Sushumna, I.; Ruckenstein, E. J. Catal. 1985, 94, 239.

(36) Egelhoff, W. F.; Steigerwald, D. A. J. Vac. Sci. Technol., A 1989, 7 , 2167.

(37) Hofmann, S.; Ducati, C.; Kleinsorge, B.; Robertson, J. Appl. Phys. Lett. 2003, 83, 135.

(38) Delzeit, L.; Chen, B.; Cassell, A.; Stevens, R.; Nguyen, C.; Meyyappan, M. Chem. Phys. Lett. 2001, 348, 368.
(39) Paal, Z.; Menon, P. G. Hydrogen Effects in Catalysis; Dekker: New York, 1988.

(40) Helveg, S.; Lopez-Cartes, C.; Sehested, J.; Hansen, P. L.; Clausen, B. S.; Rostrup-Nielsen, J. R.; Abild-Pedersen, F.; Norskov, J. K. Nature 2004, 427, 426.

(41) Jorio, A.; Souza, A. G.; Dresselhaus, G.; Dresselhaus, M. S.; Swan, A. K.; Unlu, M. S.; Goldberg, B. B.; Pimenta, M. A.; Hafner, J. H.; Lieber, C. M.; Saito, R. Phys. Rev. B 2002, 65, 155412.

(42) Telg, H.; Maultzsch, J.; Reich, S.; Hennrich, F.; Thomsen, C. Phys. Rev. Lett. 2004, 93, 177401.

(43) It is important to note that the intensity of the RBMs does not immediately give information on the absolute abundance of a certain tube species. The RBM cross section depends on diameter, chirality, and excitation energy, and so far, there is no accepted procedure to extract relative tube abundances from the Raman intensities. However, by normalizing each Raman spectrum to a given RBM, we can safely compare the relative abundance of the species seen by Raman spectroscopy as a function of catalyst thickness and deposition temperature.

(44) Kataura, H.; Kumazawa, Y.; Maniwa, Y.; Umezu, I.; Suzuki, S.; Ohtsuka, Y.; Achiba, Y. Synth. Met. 1999, 103, 2555.

(45) A variety of different $\mathrm{C} 1$ and $\mathrm{C} 2$ have been proposed. Their precise value is critical for chirality assignment. Here we only consider the SWNT diameter distribution and establish if they are metallic or semiconducting; thus the precise $\mathrm{C} 1$ and $\mathrm{C} 2$ are not critical.

(46) Bandow, S.; Asaka, S.; Saito, Y.; Rao, A. M.; Grigorian, L.; Richter, E.; Eklund, P. C. Phys. Rev. Lett. 1998, 80, 3779.

(47) Collins, P. C.; Arnold, M. S.; Avouris, P. Science 2001, 292, 706.

(48) Chen, Z. H.; Appenzeller, J.; Knoch, J.; Lin, Y. M.; Avouris, P. Nano Lett. 2005, 5, 1497.

(49) Seidel, R.; Graham, A. P.; Unger, E.; Duesberg, G. S.; Liebau, M.; Steinhoegl, W.; Kreupl, F.; Hoenlein, W. Nano Lett. 2004, 4, 831.

(50) Snow, E. S.; Novak, J. P.; Campbell, P. M.; Park, D. Appl. Phys. Lett. 2003, 82, 2145.

(51) Baker, R. T. L.; Barber, M. A. The formation of filamentous carbon; Dekker: New York, 1978

(52) Wagner, R. S.; Ellis, W. C. Appl. Phys. Lett. 1964, 4, 89.

(53) Hofmann, S.; Ducati, C.; Robertson, J.; Kleinsorge, B. Appl. Phys. Lett. 2003, 83, 135.

(54) Qi, Y.; Cagin, T.; Johnson, W. L.; Goddard, W. A. J. Chem. Phys. 2001, 115, 385.

(55) Ding, F.; Bolton, K.; Rosen, A. J. Vac. Sci. Technol., A 2004, 22, 1471.

(56) Raty, J.-Y.; Gygi, F.; Galli, G. Phys. Rev. Lett. 2005, 95, 096103.

(57) Colli, A.; Hofmann, S.; Ferrari, A. C.; Ducati, C.; Martelli, F.; Rubini, S.; Cabrini, S.; Franciosi, A.; Robertson, J. Appl. Phys. Lett. 2005, 86, 153103.

NL060068Y 